\title{
Czech multicenter research database of severe COPD
}

This article was published in the following Dove Press journal:

International Journal of COPD

10 November 2014

Number of times this article has been viewed

\section{Barbora Novotna' \\ Vladimir Koblizek' \\ Jaromir Zatloukal ${ }^{2}$ \\ Marek Plutinsky ${ }^{3}$ \\ Karel Hejduk ${ }^{4}$ \\ Zuzana Zbozinkova ${ }^{4}$ \\ Jiri Jarkovsky ${ }^{4}$ \\ Ondrej Sobotik ${ }^{5}$ \\ Tomas Dvorak ${ }^{6}$ \\ Petr Safranek ${ }^{7}$ \\ 'Department of Pneumology,} University Hospital Hradec Kralove, Charles University in Prague, Faculty of Medicine in Hradec Kralove, Hradec Kralove, ${ }^{2}$ Department of Pulmonology, University Hospital, Palacky University, Olomouc, ${ }^{3}$ Department of Pulmonology, University Hospital, Masaryk University, Brno, ${ }^{4}$ Institute of Biostatistics and Analyses, Faculty of Medicine, Masaryk University, Brno, ${ }^{5}$ Department of Pulmonology, University Hospital Motol, Charles University, Praha, ${ }^{6}$ Department of Pulmonology, Hospital Bulovka, Praha, ${ }^{7}$ Department of Pulmonology, University Hospital, Charles University, Plzen, the Czech Republic

Correspondence: Vladimir Koblizek Department of Pneumology, University Hospital Hradec Kralove, Charles University in Prague, Faculty of Medicine in Hradec Kralove, Sokolska 58I, Hradec Kralove, 500 05, the Czech Republic

Tel +420 49583477 I

Fax +420 495834773

Email vladimir.koblizek@fnhk.cz
Purpose: Chronic obstructive pulmonary disease (COPD) has been recognized as a heterogeneous, multiple organ system-affecting disorder. The Global Initiative for Chronic Obstructive Lung Disease (GOLD) places emphasis on symptom and exacerbation management. The aim of this study is examine the course of COPD and its impact on morbidity and all-cause mortality of patients, with respect to individual phenotypes and GOLD categories. This study will also evaluate COPD real-life patient care in the Czech Republic.

Patients and methods: The Czech Multicentre Research Database of COPD is projected to last for 5 years, with the aim of enrolling 1,000 patients. This is a multicenter, observational, and prospective study of patients with severe COPD (post-bronchodilator forced expiratory volume in 1 second $\leq 60 \%$ ). Every consecutive patient, who fulfils the inclusion criteria, is asked to participate in the study. Patient recruitment is done on the basis of signed informed consent. The study was approved by the Multicentre Ethical Committee in Brno, Czech Republic.

Results: The objective of this paper was to outline the methodology of this study.

Conclusion: The establishment of the database is a useful step in improving care for COPD subjects. Additionally, it will serve as a source of data elucidating the natural course of COPD, comorbidities, and overall impact on the patients. Moreover, it will provide information on the diverse course of the COPD syndrome in the Czech Republic.

Keywords: phenotypes, comorbidities, exacerbations, all-cause mortality, prospective study

\section{Introduction}

Chronic obstructive pulmonary disease (COPD) is a progressive inflammatory lung disease. ${ }^{1}$ Worldwide, the social and economic burden of COPD is increasing. ${ }^{2,3}$ The World Health Organization estimates that in 2005, 5\% of all deaths worldwide were caused by COPD. This equates to 3 million people. ${ }^{4}$ The data on its impact in the Czech Republic, and Central Europe in general, is scarce. It has been estimated that approximately $7 \%-8 \%$ of the Czech population suffers from COPD. ${ }^{5}$ The burden of the disease in the Czech Republic is considerable, and accounts for 2,500 deaths annually. ${ }^{6}$

Although causal treatment for COPD is not available, it can be successfully managed and its progression impeded by complex and multidisciplinary approaches. ${ }^{1}$ COPD is marked by a progressive airflow limitation and is confirmed by post-bronchodilator forced expiratory volume in 1 second $\left(\mathrm{FEV}_{1}\right)$ /forced vital capacity $<0.70 .{ }^{1}$ The level of lung function decline varies in individual cases. ${ }^{7}$ Nishimura et al has shown that during a prolonged follow-up, patients can be classified as 
rapid decliners, slow decliners, or sustainers. ${ }^{8}$ COPD is marked by periods of relative stability and sudden lung function deteriorations called acute exacerbations. ${ }^{9}$ It is a heterogeneous condition with several clinical phenotypes: phenotype with chronic bronchitis, emphysema-dominant phenotype, phenotype with frequent exacerbations, and asthma-COPD overlap syndrome. ${ }^{10,11}$ COPD associated with bronchiectasis and pulmonary cachexia can be considered as variants of the disease. ${ }^{1,12}$ In addition to patients with a clearly dominant phenotype, cases sometimes present with mixed disease forms. ${ }^{13}$

The presentation of symptoms of COPD in patients fluctuates and does not closely correlate with $\mathrm{FEV}_{1}$ decline, and its impact on quality of life varies. ${ }^{714}$ Patients can be classified into four categories according to the severity of dyspnea, symptom presentation, the number of exacerbations, and $\mathrm{FEV}_{1}$. These are: 1) low risk, few symptoms; 2) low risk, more symptoms; 3) high risk, few symptoms; 4) high risk, more symptoms. ${ }^{1,12}$ GOLD recommend using the modified Medical Research Council dyspnea scale (mMRC) or COPD Assessment Test (CAT) to evaluate symptoms and breathlessness. ${ }^{1}$ In the Czech Republic, CAT and $\mathrm{mMRC}$ questionnaires are routinely used in the disease management. ${ }^{12}$

The Czech Pneumological and Phthiseological Society adopted the GOLD strategy with a four-step modification to the treatment algorithm, with added emphasis on treatment targeted to phenotypes and personalized care. ${ }^{12}$ The Czech Pneumological and Phthiseological Society COPD guidelines recommend the mMRC cutoff point as $\geq 1 .{ }^{15}$

The aim of the Czech Multicentre Database of COPD is to establish the real clinical course of severe forms of COPD, establish the cause for deterioration of clinical status of the patients, and describe the progression of the disease to death.

This paper summarizes the methodology of the Czech Multicentre Database of COPD.

\section{The objective}

The primary objective of the Czech Multicentre Database of COPD is to assess the all-cause mortality in patients with severe COPD (post-bronchodilator $\mathrm{FEV}_{1} \leq 60 \%$ ) in real time in the Czech Republic. Participation in this study is offered to all patients in the participating centers who meet the inclusion criteria and have none of the exclusion criteria. The secondary objectives consist of assessment of patients' morbidity: exacerbation of COPD, acute non-COPD respiratory events, acute non-respiratory events, cancers, and coronary artery disease. The tertiary objectives are: monitoring lung function decline, COPD-related symptoms presentation, adherence to inhaled medication, and physical activity deterioration. The analysis will concentrate on the differences between various COPD phenotypes and GOLD categories, and their progression over time.

\section{Design}

The Czech Multicentre Research Database of COPD is a multicenter, observational, and prospective database of severe COPD patients. The participants have access to full and complex medical care. The study is projected to go on for 5 years after the enrollment of the last patient, or until a statistically significant number of deaths occur (Figure 1). Patient follow-up is conducted every 6 months. The aim is to enroll 1,000 patients and follow the course of their disease.

Currently, twelve investigating centers are participating. The centers were set up to cover most of the Czech Republic (Figure 2). The participating centers are: University Hospital Hradec Kralove, University Hospital Brno, University Hospital Olomouc, University Hospital Ostrava, University Hospital Plzen, University Hospital Motol in Prague, Hospital Bulovka in Prague, Thomayer Hospital in Prague, Regional Hospital Jihlava, Regional Hospital Liberec, Masaryk Hospital in Usti nad Labem, and Regional Hospital of T Bata in Zlin.

COPD and its impact in the Czech Republic has not been studied in such detail before, making it the first of its kind.

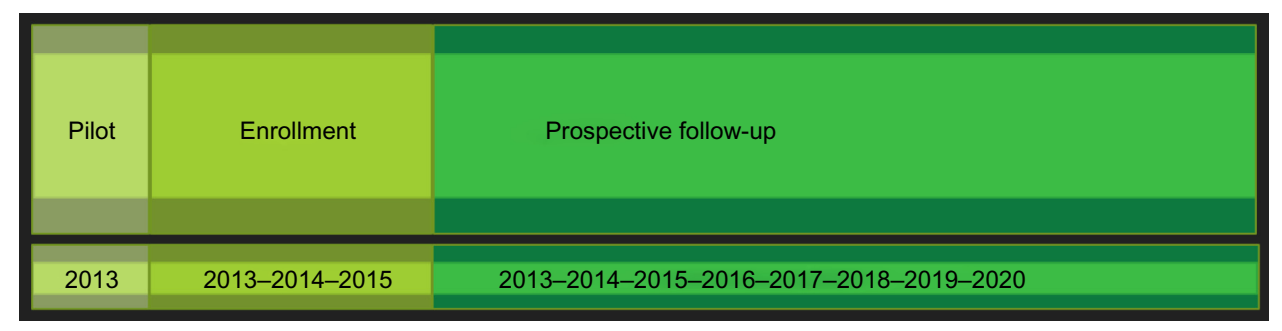

Figure I The time schedule of the Czech Multicentre Research Database of Severe COPD.

Note: The prospective follow-up period can be extended, if necessary, due to statistical analysis of all-cause mortality.

Abbreviation: COPD, chronic obstructive pulmonary disease. 


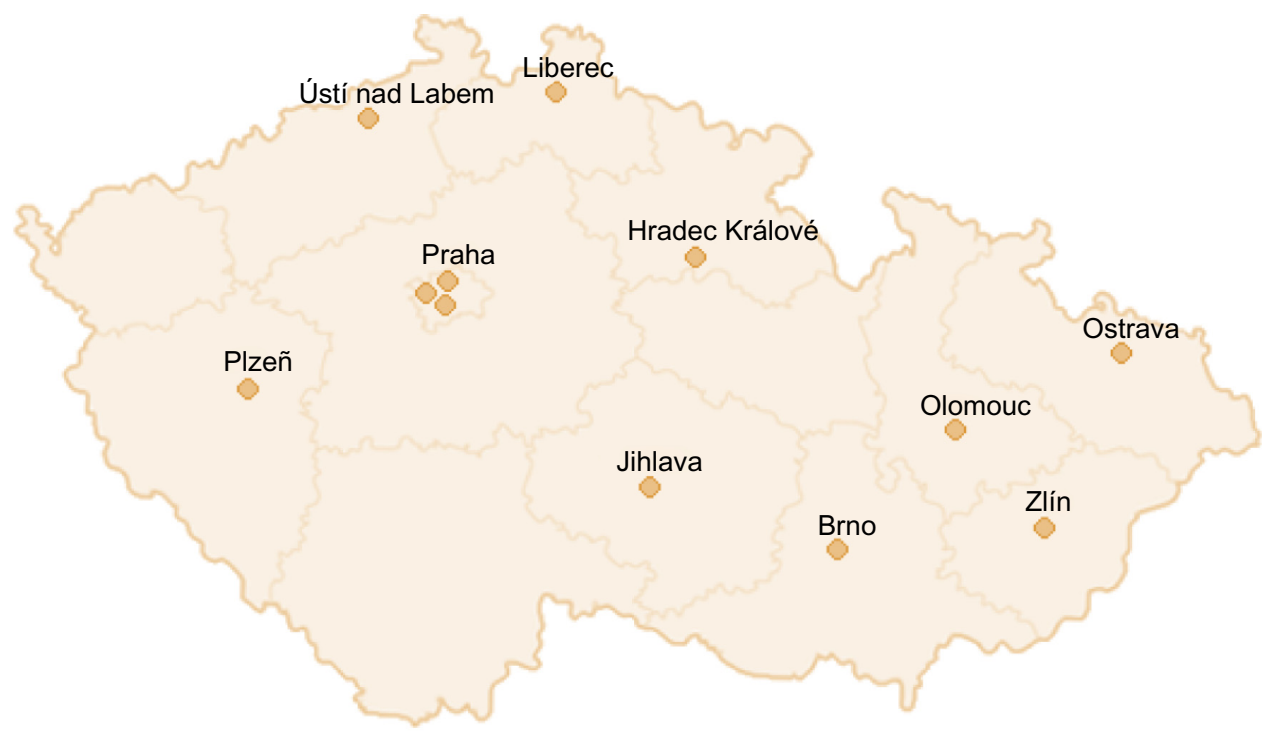

Figure 2 The twelve participating centers in the Czech Republic.

The data will be obtained through regular check-ups every 6 months, as well as in hospital data records search.

The study is being conducted in accordance with Czech and European Union laws. The study and its protocol were approved by The Multicentre Ethical Committee in Brno, Czech Republic as well as ethics and review boards of all individual participating centers. The Czech Multicentre Research Database of COPD has been registered by the State Institute for Drug Control (SUKL) under the number 1301100001, as well as Clinicaltrials.gov under the NLM identifier NCT01923051. More information can be found at http://chopn.registry.cz/index-en.php.

\section{Patient participation}

Participating patients are 18 years and older, and both sexes are eligible. The main inclusion criteria are: a diagnosis of $\mathrm{COPD}$, post-bronchodilator $\mathrm{FEV}_{1} \leq 60 \%$, patient condition deemed stable (without disease exacerbation for minimum of 8 weeks prior to enrollment), written consent, and home address in proximity to the research center.

The diagnosis of COPD is made on the basis of exposition to one or more risk factors for the development of COPD, presence of respiratory symptoms, and an irreversible bronchial obstruction in the absence of a respiratory infection. Patients are excluded from the study if there are any doubts in the diagnosis of COPD.

Patients are excluded on the grounds of: cystic fibrosis diagnosis, bronchial asthma, or bronchiectasis without a definite diagnosis of COPD, terminal stages of a malignancy (respiratory or non-respiratory with predicted survival $<3$ months), end-stage COPD (predicted survival $<3$ months), uncooperative patient, or considerable mobility impairment (bed-to-chair activity level).

\section{Study protocol}

The study protocol is conceived to evaluate the progression of patient symptoms, quality of life, depression, lung function, and physical abilities in time. All of the parts of the protocol are repeated regularly throughout the participation of the subject in the study. Table 1 provides a concise data collection scheme.

A detailed patient history including comorbidities and medications used (respiratory and other) is recorded. A detailed history of exposure to inhalation risks is documented. This includes patient occupation, exposure to secondhand smoke, current smoking status, and the amount of cigarettes smoked over time in pack-years.

The comorbidities and their treatment are noted by asking a set of specific comorbidity-related questions (Table 2) and by a search through hospital records.

Respiratory symptoms and shortness of breath are assessed by the CAT and mMRC dyspnea scale, respectively. The Sino-Nasal Outcome Test (SNOT-22), a questionnaire used to assess the quality of life of patients with chronic rhinosinusitis, is evaluated once a year. Quality of life is measured by the St George's Respiratory Questionnaire (SGRQ) questionnaire. ${ }^{16,17}$

Depressive symptoms are evaluated through the Zung Self-Rating Depression Scale and Beck Depression Inventory Short Form; both are self-administered short questionnaires. The Zung questionnaire consists of 20 items regarding affective, psychological, and somatic symptoms of depression. Questions are scored on a scale of one through four, making 
Table I Data collection scheme

\begin{tabular}{|c|c|c|c|c|}
\hline Appointment type & $\begin{array}{l}\text { Baseline appointment } \\
\text { (stable COPD) }\end{array}$ & $\begin{array}{l}\text { Planned appointment } \\
\text { (stable COPD) }\end{array}$ & $\begin{array}{l}\text { Emergency appointment } \\
\text { (with or without hospitalization) }\end{array}$ & $\begin{array}{l}\text { End of } \\
\text { study }\end{array}$ \\
\hline Appointment interval & Registry enrollment & Every 6 months & $\begin{array}{l}\text { In the event of emergency } \\
\text { hospitalization (ie, not } \\
\text { planned hospitalization) }\end{array}$ & \\
\hline Appointment number & 1 & $2-11$ & EI, E2, E3 ... & \\
\hline$\checkmark$ Informed consent & $x$ & & & \\
\hline$\checkmark$ Patient history & $x$ & $x$ & & \\
\hline$\checkmark$ Demographic data & $x$ & & & \\
\hline Risk factors & $x$ & $x$ & & \\
\hline$\checkmark$ Symptoms (mMRC, CAT***) & $x$ & $x$ & & \\
\hline Quality of life (SGRQ) & $x$ & $x$ & & \\
\hline$\checkmark$ Current medications & $x$ & $x$ & & \\
\hline$\checkmark$ Physical examination & $x$ & $x$ & & \\
\hline ECG & $x$ & $X^{*}$ & & \\
\hline Laboratory test (AIAT) & $x$ & & & \\
\hline$\checkmark$ Frequency of exacerbations & $x$ & $X^{*}$ & & \\
\hline$\checkmark$ Nasal symptoms (SNOT-22)**** & $x$ & $X^{*}$ & & \\
\hline$\checkmark$ Lung function & $x$ & $x$ & & \\
\hline Arterial blood gases & $x$ & $x$ & & \\
\hline$\checkmark 6 \mathrm{MWT} * * *$ & $x$ & $x$ & & \\
\hline Pedometer $\left(\mathrm{ADL}^{\circ}\right)$ & $x$ & $X^{*}$ & & \\
\hline Depression questionnaires & $x$ & $x$ & & \\
\hline Chest HRCT & $x$ & $X^{\S}$ & & \\
\hline Echocardiography & $x$ & $X^{* *}$ & & \\
\hline DEXA & $x$ & & & \\
\hline Skinfold anthropometry & $x$ & $X^{*}$ & & \\
\hline Compliance assessment & $x$ & $X^{*}$ & & \\
\hline $\begin{array}{l}\text { Blood sample }\left(-70^{\circ} \mathrm{C}\right)- \\
\text { genomic analysis }\end{array}$ & $\mathrm{X}$ & & & \\
\hline $\begin{array}{l}\text { Reason for sudden hospital } \\
\text { admission }\end{array}$ & & & $x$ & \\
\hline $\begin{array}{l}\text { Patient progress during } \\
\text { admission }\end{array}$ & & & $x$ & \\
\hline Patient self-withdrawal from study & & & & $x$ \\
\hline$\checkmark$ Cause of death & & & & $x$ \\
\hline 5-year survival & & & & $x$ \\
\hline
\end{tabular}

Notes: $\checkmark$ Mandatory. ${ }^{*}$ Once a year. **During the third and fifth year of study. ${ }^{\circ}$ Monthly average. ${ }^{\S}$ During the fifth year of study. ${ }^{* * *}$ Mandatory, but with the option "unable to perform".

Abbreviations: 6MWT, 6-minute walking test; AIAT, $\alpha$ I-antitrypsin; ADL, activity of daily living; CAT, COPD Assessment Test; COPD, chronic obstructive pulmonary disease; DEXA, dual energy X-ray absorptiometry; EI-E3, emergency appointment I-3; ECG, electrocardiography; HRCT, high-resolution computer tomography; mMRC, modified Medical Research Council dyspnea scale; SGRQ, St George’s Respiratory Questionnaire; SNOT-22, Sino-Nasal Outcome Test.

the minimum possible score 20 and the maximum 80 . Scores in the range of 20-49 indicate normal mood, 50-59 mild depression, 60-69 moderate depression, and $\geq 70$ severe depression. The Beck questionnaire contains 13 items, each scored by zero to three points, making the maximum possible score 39 . Scores in the range of 5-8 indicate mild depression, 8-16 indicate moderate depression, and scores $\geq 16$ are assessed as severe depression.

Patients are asked about the presence of fatigue, dry cough, productive cough, the signs of blood in expectorate, and purulent sputum. The physical examination includes chest excursion difference, abnormal breath sounds, clubbed fingers, and chest deformity notation. Fat-free mass index and body composition is measured once a year through skinfold anthropometry. The Morisky Four-Item Self-Report Measure of Medication-taking Behavior and a five-step inhaler technique assessment are evaluated once a year.

The 6-minute walking test, post-bronchodilator pulmonary function tests (spirometry, body plethysmography, fractional exhaled nitric oxide, and transfer factor measurement), and arterial blood gases (at rest, without supplementary oxygen) are measured at every follow-up. Fractional exhaled nitric oxide is measured by Medisoft FeNO+ (Medisoft, Sorinnes, Belgium). The methodology 
Table 2 Tracked comorbidities and their treatment

\begin{tabular}{ll}
\hline Comorbidities & Treatment \\
\hline $\begin{array}{l}\text { Bronchial asthma in the personal history } \\
\text { Bronchial asthma currently }\end{array}$ & \\
Coronary artery disease (stable angina) & $\begin{array}{l}\text { Pharmacotherapy } \\
\text { involving statins }\end{array}$ \\
(ST elevation myocardial infarction) & Angioplasty \\
Coronary artery disease & Surgery \\
(non-ST elevation myocardial infarction) & \\
Heart failure & Diuretics \\
& B-blockers \\
& $\begin{array}{l}\text { Angiotensin-converting } \\
\text { enzyme inhibitors }\end{array}$ \\
Atrial fibrillation & Pharmacotherapy \\
Arterial hypertension & Electroversion \\
Arrhythmia and/or syncope & Pharmacotherapy \\
and/or palpitation & Pacemaker \\
Malignancy & Implantable cardioverter \\
Osteoporosis & defibrillator \\
Diabetes & \\
Anemia & \\
Depression & \\
Peptic ulcer & \\
Sleep apnea syndrome & \\
\hline
\end{tabular}

of all pulmonary lung function tests follows American Thoracic Society/European Respiratory Society standards. Post-bronchodilator pulmonary function tests are performed regardless of whether the patient has used a long-term bronchodilator prior to the exam. Electrocardiography (ECG) is recorded once a year.

Activity of daily living is assessed via a pedometer which is worn by the participants every day for 1 month a year, during a period of non-exacerbation. Patients receive a Yamax SW-500 pedometer (Yamasa Tokei Keiki Co., Ltd., Tokyo Japan) and are instructed to wear it every day from the moment they wake up until they go to bed, for a period of 30 days, and note down the total number of steps made every day. The instructions are provided by either a physician or a study nurse. Weekly averages are recorded into the study.

The subject is classified into a GOLD category at every scheduled visit, using post-bronchodilator $\mathrm{FEV}_{1}$ and the CAT, mMRC, and SGRQ questionnaires. COPD phenotypes are assessed at the first study visit and may be updated with disease progression (Table 3). This classification is subjective and will be compared to the "objective" patient classification which is calculated from all data available in the electronic case report form (e-CRF). ${ }^{1}$

Participants are screened by echocardiography at enrollment, and during the third and fifth year of the study. High-resolution computed tomography (HRCT) is ordered at admission and then at fifth year of the study. HRCT is assessed centrally by one radiology consultant. Emphysema, bronchiectasis, fissures, mucosal plugs, atelectasis, nodules, ground glass opacity, lymphadenopathy, air trapping, and the size of major vessels are evaluated in the HRCT. Full body DEXA is recommended for osteoporosis screening as well as body composition analysis at enrollment (see above).

Participants are screened for $\alpha 1$-antitrypsin (A1AT) deficiency upon recruitment to the study. A1AT deficiency screening should be performed in all participating centers. Upon positive results for A1AT deficiency, further genetic testing is performed. All patients positive for A1AT

Table 3 Definitions of clinical phenotypes used in this study

\begin{tabular}{|c|c|c|}
\hline Clinical phenotype & Simplified specification & Notes \\
\hline Chronic bronchitis & The patient answers yes to both questions about & \\
\hline phenotype & chronic presence of cough and expectoration & \\
\hline Emphysematous & Radiology specialist says yes to the assessment & \\
\hline phenotype & of pulmonary emphysema by chest HRCT & \\
\hline COPD with & Defined by presence of bronchiectasis & Chronic presence of cough and expectoration is not required \\
\hline bronchiectasis & (in two or more lobes) on a chest HRCT & \\
\hline \multirow{5}{*}{$\begin{array}{l}\text { Asthma-COPD } \\
\text { overlap syndrome }\end{array}$} & Definite COPD subjects met two or more & Major: strong bronchodilator test positivity $\left(\mathrm{FEV}_{1}>15 \%\right.$ and \\
\hline & major or one major plus two minor criteria ${ }^{10,12}$ & $>400 \mathrm{~mL})$, bronchial challenge test positivity, FeNO $\geq 45-50 \mathrm{ppb}$ \\
\hline & & and/or sputum eosinophils $\geq 3 \%$, history of asthma \\
\hline & & Minor: mild bronchodilator test positivity $(\mathrm{FEV},>12 \%$ and \\
\hline & & $>200 \mathrm{~mL}), \uparrow$ total immunoglobulin E, history of atopy \\
\hline Frequent exacerbation & Two or more acute exacerbations per year & \\
\hline phenotype & & \\
\hline Pulmonary cachexia & $\mathrm{BMI}<2 \mathrm{I} \mathrm{kg} / \mathrm{m}^{2}$ in absence of another valid reason & \\
\hline phenotype & & \\
\hline
\end{tabular}

Abbreviations: BMI, body mass index; COPD, chronic obstructive pulmonary disease; FeNO, fractional exhaled nitric oxide; FEV ${ }_{1}$, forced expiratory volume in I second; HRCT, high-resolution computed tomography. 
deficiency are treated centrally at The Thomayer Hospital in Prague. Information about the treatment of A1AT-deficient patients is captured in the registry.

Blood samples will be taken at six university centers. Genomic analyses and analyses of protein profiles will be performed in a central laboratory at The University Olomouc. Analysis of genes associated with COPD (CHRNA3, CHRNA5, HHIP, FAM13A, IL33, IL1-RL1, and other proteincoding genes) will be performed by MassARRAY ${ }^{\circledR}$ (Sequenom, Inc., San Diego, CA, USA) using polymerase chain reaction and matrix-assisted laser desorption/ionization time-of-flight mass spectrometry. Analyses of cytokines and other proteins (TNF- $\alpha$, IL6, IL8, GM-CSF, M-CSF, PECAM1, CCL19, CCL21, MCP1, MPO, and others) will be performed by using immuno-polymerase chain reaction, Luminex ${ }^{\circledR}$ assays, enzyme-linked immunosorbent assay, and quantitative polymerase chain reaction. Outcomes of genomic and protein analyses will be assessed in relation to severity, phenotypes, and other clinical characteristics of COPD.

Disease exacerbations are identified by targeted inquiry and a search through hospital records. Treatment of COPD exacerbations is noted. A COPD exacerbation is defined as a deterioration of COPD symptoms a need for antibiotic treatment and/or corticosteroids (oral or intravenous).

Hospitalizations (pulmonary and other) and their course are recorded as well. In the event of death, the causes will be examined. Clinical autopsy is recommended for all patients whose death occurs in a hospital.

Certain parts of the study are assessed centrally either due to their specialized nature or to ensure standardized interpretation of results. The following tests are evaluated centrally: HRCT, ECG, activity of daily living, and the Zung, Beck, SGRQ, and SNOT-22 questionnaires.

All participants have the right to refuse parts of the study protocol or withdraw from the study at any point (Table 1).

\section{Obstacles in data collection}

The considerable size of this study presents various challenges for the study team. The authors recommend that all parts of the study are completed for every enrolled patient. However, with the declining health status of enrolled patients, some sections of the study will have to be omitted due to an inability to perform the test or, in certain cases, due to unwillingness to complete parts of the study. With declining lung functions and mobility, some patients have to be excluded from the 6-minute walking test. Immobile patients who are unable to travel are flagged as "living, but unable to travel". Telephone contact is maintained with the patient, or family members, or their general practitioner.

Questionnaires are time consuming and, as such, some participants see them as a burden and may decide to not complete them. Zung and Beck questionnaires regarding depression are refused by some patients due to the stigma they associate with mental illness.

It is up to the individual physician to come to an understanding and a compromise with their patient, regarding the extent to which the patient wants to participate in the study. The study sections have been divided into mandatory and recommended parts. The failure to obtain mandatory data deems the patient non-valid. Patient flagged as non-valid is excluded from data analysis. Table 1 provides a list of the mandatory and recommended study sections.

\section{Safety assessment}

Participation in the Czech Multicentre Research Database of COPD is deemed, at most, without a significant health hazard. Nevertheless, collection of arterial blood and both imaging methods (HRCT and DEXA) using radiation may potentially pose some risk. These risks are comparable to routine clinical practice for patients with severe COPD. Professional guarantee is assured by the Czech Pneumological and Phthiseological Society and Institute of Biostatistics and Analyses, Masaryk University.

\section{Analysis}

Standard descriptive statistics will be used in the analyses. Categorical variables will be described by absolute and relative frequencies of categories in the base for given computation. The median supplemented by the fifth to 95 th percentile range will be used for continuous variables. Valid $\mathrm{N}$ will be reported in the case of missing values in the continuous variables. Parametric statistics will be used as an additional approach when appropriate: the mean supplemented by standard deviation or $95 \%$ confidence interval will be adopted for continuous variables when the normality of data is proven by the Kolmogorov-Smirnov test. The geometric mean and its $95 \%$ confidence interval will be adopted for log-normally distributed data.

Statistical significance of differences in continuous variables between/among groups of patients will be analyzed using the Mann-Whitney $U$ test and Kruskal-Wallis test. Student's $t$-test for two groups or analysis of variance followed by Tukey's post hoc test for three or more groups will be adopted when appropriate as an additional analysis approach. The paired $t$-test and/or Wilcoxon paired test will be used for 
analyzing statistical significance of differences of continuous variables between study time points. McNemar's test will be used for the same purpose for categorical variables. Factors influencing binary endpoints without time to event and censoring (eg, 1-year mortality) will be analyzed using logistic regression, and general linear models will be adopted for quantitative endpoints (eg, $\mathrm{FEV}_{1} \%$ and its change), with proven confounding factors as covariates.

The survival data will be visualized using Kaplan-Meier methodology and the statistical significance of differences in survival among groups of patients will be tested by a log-rank test. Cox proportional hazards model will be adopted for the analysis of potential predictors of time to event endpoints (eg, mortality, exacerbations).

The level of statistical significance in all analyses will be $\alpha=0.05$. All alternative hypotheses will be two-sided. Analyses will be performed using SPSS $^{\circledR}$ 22.0.0 (IBM Corporation, Armonk, NY, USA) and $R$.

\section{Discussion}

The Czech Multicentre Research Database of COPD is a multicenter, observational, and prospective database of severe COPD patients, devoted to patients with highest forms of pulmonary obstruction without the exclusion of patients with bronchiectasis and asthma-COPD overlap syndrome.

COPD can be considered a syndrome rather than a simple disease, as it is characterized by a myriad of forms and features. ${ }^{14}$ If successful, the Czech Multicentre Research Database of COPD will provide data on the mortality and morbidity of patients with COPD in the Czech Republic, as well as a detailed look at the course and pitfalls of the disease.

The disease is often associated with comorbidities. The most significant being: cardiovascular disease, lung carcinoma, cachexia, and osteoporosis. ${ }^{18}$ Generally, comorbidities significantly contribute to disease severity, and the patients often have several comorbidities at one time. ${ }^{19} \mathrm{COPD}$ patients with a greater number of comorbidities have a higher yearly rate of hospitalizations as well as higher hospitalization mortality. ${ }^{20}$ Comorbidity analysis will elucidate the burden of COPD on the patients as well as the Czech health care system.

Due to the strong association between cardiovascular disease and COPD, ECG screening is a fast, easy, and readily available option, as anomalies in P-waves are associated with both cardiovascular and pulmonary disease. ${ }^{21}$ Abnormal P-wave axis, even when adjusted for age, sex, and morbidity, is associated with increased risk of death. ${ }^{22}$ Abnormal cardiac repolarization, a risk factor for sudden cardiac death, has been found to be prevalent in one-third of COPD patients. ${ }^{23}$ Prolonged QT dispersion was prolonged in COPD patients, and may be related to hypoxia. ${ }^{23}$

Echocardiography is a noninvasive and fast method, which can be used to screen for numerous cardiac functional and structural cardiac abnormalities. ${ }^{24}$ COPD is associated with pulmonary hypertension, ventricular dysfunction, atherosclerosis, and heart failure. Early diagnosis and monitoring are enhanced with improved imaging techniques and are vital in ensuring better mortality outcomes. ${ }^{25,26}$ ECG and echocardiography screenings can serve as early detection to cardiovascular events and subsequent analysis may show structural and functional cardiac abnormalities in COPD patients.

Weight loss leading to cachexia is a major issue in any chronic disease and is a consequence of a combination of abnormal metabolism and lower food intake. ${ }^{27}$ There is a strong link between cachexia and mortality risk, even though no known unifying mechanism has been proposed. ${ }^{28}$ Higher body mass index in patients with COPD is a predictor of better long-term survival in patients hospitalized for COPD exacerbations. ${ }^{29}$ Using the fat-free mass index measured by anthropometry and DEXA instead of the body mass index, will allow a more specific mortality analysis of pulmonary cachexia to be performed. This is because the fat-free mass index takes into account the muscle mass of the subject rather than total mass.

COPD is associated with lower bone mineral density and has a high prevalence of osteoporosis. ${ }^{30-32}$ This may be because tobacco smoking, systemic inflammation, vitamin $\mathrm{D}$ deficiency, and the use of oral or inhaled corticosteroids are common risk factors of both COPD and osteoporosis. ${ }^{33}$

The limiting nature of COPD has a negative impact on patients' quality of life, which is associated with disease severity and depression. ${ }^{34}$ Depressive disorders negatively impact physical fitness and interfere with compliance to physical therapy and worsen the symptoms of the disease. ${ }^{35-38}$

Management of a chronic illness requires patient cooperation and adherence to medication. This is crucial in preventing the disease from being socially limiting. ${ }^{34-39}$ Compliance and adherence to inhalation medication largely depends on a subjective feeling of relief after inhalation, and device "ease of use" ${ }^{40}$ Greater compliance is associated with fewer exacerbations and hospitalizations due to exacerbations, so patient education should be an inherent part of clinical practice..$^{37,39-41}$

$\mathrm{FEV}_{1}$ assessment has remained the main endpoint in the development of new COPD therapies. However, COPD 
is a heterogeneous disease and $\mathrm{FEV}_{1}$ evaluation alone is not sufficient enough to show the disease progression. Emphysematous destruction, regional ventilation abnormalities (ventilation defects), airway remodeling, and gas trapping can be shown by thoracic imaging methods in COPD patients with modest lung function decline. ${ }^{42}$ CT may be used to define COPD phenotypes and help optimize treatment. ${ }^{43} \mathrm{CT}$ screening helps detect possible cancerous lung lesions at an earlier stage and decrease lung cancer mortality. ${ }^{44}$

This study is designed to take a closer look at this complex disease. The strength of this study is that it is a pharmacologically noninterventional study design. Registered patients are screened for heart disease by ECG monitoring, echocardiography, and chest CT, which allows for early disease detection and treatment. Chest CT and ECG are assessed centrally by one designated specialist for all study centers.

Unfortunately, not all of the patients are able or willing to go through the whole examination process. For example, with declining lung functions, the patients will not be able to perform the 6-minute walking test without supplementary oxygen. The exclusion of severely immobile subjects who have the highest mortality risk will be excluded at enrollment and may cause some bias in data analysis.

This study will help physicians understand the development of the disease and to identify the future risks their patients face. The establishment of the database is a useful step in viewing various aspects of COPD with severe bronchial obstruction. Additionally, it will serve as a source of data elucidating the natural course of the COPD, comorbidities, and overall impact on the patients. Moreover, it will provide information on the diverse course of the COPD syndrome. Prospective follow-up allows for assessment of the importance of phenotypic view in this field. Finally, the uniform enrollment procedure presents an opportunity to harmonize COPD care.

\section{Acknowledgments}

The authors would like to thank the Czech Pneumological and Phthiseological Society for their ongoing support, namely, Professor V Kolek (The President of the Czech Pneumological and Phthiseological Society), Professor M Marel (The Scientific Secretary of the Czech Pneumological and Phthiseological Society), and Associate Professor L Dusek (The Director of Institute of Biostatistics and Analyses, Masaryk University) for their indispensable assistance with initialization of this project.
Furthermore, the authors are grateful to all of the experts responsible for the creation of the design of various subsections of this database: T Pavlik and J Svancara (statistical analysis), E Kocova (radiology), K Neumannova (activity of daily living), M Hronek and M Kovarik (anthropometry), L Pavlikova (densitometry), M Vytrisalova (compliance assessment), and R Praus, M Kopecky, M Orban, and $\mathrm{T}$ Konecny (cardiology). The authors would also like to thank the following physicians for their role in the implementation of this project at their study sites and their support with design finalization: A Vlachova, L Heribanova, S Jaresova, N Pauk, P Popelkova, B Snelerova, P Musilova, M Majerciakova, and T Vencalek.

The Czech Multicentre Research Database of COPD has been given funding via unrestricted grants from the following companies: AstraZeneca, Boehringer Ingelheim, GlaxoSmithKline, Medicom International s.r.o., Novartis, Pfizer, and Takeda.

The Czech Multicentre Research Database of COPD is supported by a grant from the Czech Ministry of Health (grant number 15/14/NAP, The incidence of A1AT deficiency in patients with a severe form of COPD). Additionally, this project is supported by $\mathrm{MH} \mathrm{CZ}-\mathrm{DRO}$ (UHHK, 00179906) and by MH CZ NT13531-3/2013.

\section{Author contributions}

All authors contributed toward data analysis, drafting and revising the paper and agree to be accountable for all aspects of the work. The study design was created by V Koblizek, K Hejduk, J Jarkovsky, and Z Zbozinkova. V Koblizek, J Zatloukal, M Plutinsky, O Sobotik, T Dvorak, and P Safranek are the professional guarantors of the project. The case report form was edited to its final form by B Novotna. The manuscript was written by B Novotna, V Koblizek, and $\mathrm{K}$ Hejduk. The manuscript was edited by Z Zbozinkova.

\section{Disclosure}

The authors report no conflicts of interest in this work.

\section{References}

1. Global Initiative for Chronic Obstructive Lung Disease. Global Strategy for the Diagnosis, Management, and Prevention of Chronic Obstructive Pulmonary Disease. Leuven: Global Initiative for Chronic Obstructive Lung Disease; 2014. Available from: http://www.goldcopd. org/uploads/users/files/GOLD_Report_2014_Jun11.pdf. Accessed September 18, 2014.

2. Ferkol T, Schraufnagel D. The global burden of respiratory disease. Ann Am Thorac Soc. 2014;11(3):404-406.

3. Patel JG, Nagar SP, Dalal AA. Indirect costs in chronic obstructive pulmonary disease: a review of the economic burden on employers and individuals in the United States. Int J Chron Obstruct Pulmon Dis. 2014;9:289-300. 
4. Fact sheet no 315: chronic obstructive pulmonary disease (COPD) [webpage on the Internet]. Geneva: World Health Organization; 2008 [updated October 2013]. Available from: http://www.who.int/mediacentre/factsheets/fs315/en/. Accessed September 18, 2014.

5. Maly M, Zvolsky M, Rozborilova E, Vondra V. Respiratory mortality in Czech and Slovak Republics in the year 2011. Stud Pneumol Phtiseol. 2013;79(4):128-132.

6. Vondra V. Between 1996 and 2005, COPD mortality has doubled. Stud Pneumol Phtiseol. 2007;73(2):75-77.

7. Vestbo J, Edwards LD, Scanlon PD, et al. Changes in forced expiratory volume in 1 second over time in COPD. $N$ Engl $J$ Med. 2011;365(13):1184-1192.

8. Nishimura M, Makita $\mathrm{H}$, Nagai $\mathrm{K}$, et al. Annual change in pulmonary function and clinical phenotype in chronic obstructive pulmonary disease. Am J Respir Crit Care Med. 2012;185(1):44-52.

9. Donaldson GC, Wedzicha JA. COPD exacerbations.1: epidemiology. Thorax. 2006;61(2):164-168.

10. Miravitlles M, Soler-Cataluna JJ, Calle M, et al. A new approach to grading and treating COPD based on clinical phenotypes: summary of the Spanish COPD guidelines (GesEPOC). Prim Care Respir J. 2013;22(1):117-121.

11. Louie S, Zeki AA, Schivo M, et al. The asthma-chronic obstructive pulmonary disease overlap syndrome: pharmacotherapeutic considerations. Expert Rev Clin Pharmacol. 2013;6(2):197-219.

12. Koblizek V, Chlumsky J, Zindr V, et al. Chronic obstructive pulmonary disease: official diagnosis and treatment guidelines of the Czech Pneumological and Phthisiological Society; a novel phenotypic approach to COPD with patient-oriented care. Biomed Pap Med Fac Univ Palacky Olomouc Czech Repub. 2013;157(2):189-201.

13. Ogawa E, Nakano Y, Ohara T, et al. Body mass index in male patients with COPD: correlation with low attenuation areas on CT. Thorax. 2009;64(1):20-25

14. Vestbo J, Agusti A, Wouters EF, et al. Should we view chronic obstructive pulmonary disease differently after ECLIPSE? A clinical perspective from the study team. Am J Respir Crit Care Med. 2014;189(9):1022-1030.

15. Jones PW, Adamek L, Nadeau G, Banik N. Comparisons of health status scores with MRC grades in COPD: implications for the GOLD 2011 classification. Eur Respir J. 2013;42(3):647-654.

16. Jones PW, Brusselle G, Dal Negro RW, et al. Patient-centred assessment of COPD in primary care: experience from a crosssectional study of health-related quality of life in Europe. Prim Care Respir J. 2012;21(3):329-336.

17. Ringbaek T, Martinez G, Lange P. A comparison of the assessment of quality of life with CAT, CCQ, and SGRQ in COPD patients participating in pulmonary rehabilitation. COPD. 2012;9(1):12-15.

18. Decramer M, Janssens W. Chronic obstructive pulmonary disease and comorbidities. Lancet Respir Med. 2013;1(1):73-83.

19. Vanfleteren LE, Spruit MA, Groenen M, et al. Clusters of comorbidities based on validated objective measurements and systemic inflammation in patients with chronic obstructive pulmonary disease. Am J Respir Crit Care Med. 2013;187(7):728-735.

20. Baty F, Putora PM, Isenring B, Blum T, Brutsche M. Comorbidities and burden of COPD: a population based case-control study. PLoS One. 2013;8(5):e63285.

21. Lazovic B, Mazic S, Stajic Z, Djelic M, Zlatkovic-Svenda M, Putnikovic B. United in prevention-electrocardiographic screening for chronic obstructive pulmonary disease. Acta Inform Med. 2013;21(2):127-128

22. LiY, Shah AJ, Soliman EZ. Effect of electrocardiographic P-wave axis on mortality. Am J Cardiol. 2014;113(2):372-376.

23. Sievi NA, Clarenbach CF, Camen G, Rossi VA, van Gestel AJ, Kohler M. High prevalence of altered cardiac repolarization in patients with COPD. BMC Pulm Med. 2014;14:55.

24. Mazurek J, Forfia PR. Enhancing the accuracy of echocardiography in the diagnosis of pulmonary arterial hypertension: looking at the heart to learn about the lungs. Curr Opin Pulm Med. 2013;19(5): 437-445.
25. Rahaghi FN, van Beek EJ, Washko GR. Cardiopulmonary coupling in chronic obstructive pulmonary disease: the role of imaging. Thorac Imaging. 2014;29(2):80-91.

26. de Miguel Diez J, Chancafe Morgan J, Jimenez Garcia R. The association between COPD and heart failure risk: a review. Int J Chron Obstruct Pulmon Dis. 2013;8:305-312.

27. Ebner N, Steinbeck L, Doehner W, Anker SD, von Haehling S. Highlights from the 7th Cachexia Conference: muscle wasting pathophysiological detection and novel treatment strategies. J Cachexia Sarcopenia Muscle. 2014;5(1):27-34.

28. Kalantar-Zadeh K, Rhee C, Sim JJ, Stenvinkel P, Anker SD, Kovesdy CP. Why cachexia kills: examining the causality of poor outcomes in wasting conditions. J Cachexia Sarcopenia Muscle. 2013;4(2):89-94.

29. Lainscak M, von Haehling S, Doehner W, et al. Body mass index and prognosis in patients hospitalized with acute exacerbation of chronic obstructive pulmonary disease. $J$ Cachexia Sarcopenia Muscle. 2011;2(2):81-86.

30. Dam TT, Harrison S, Fink HA, Ramsdell J, Barrett-Connor E. Bone mineral density and fractures in older men with chronic obstructive pulmonary disease or asthma. Osteoporos Int. 2010;21(8):1341-1349.

31. Hattiholi J, Gaude GS. Bone mineral density among elderly patients with chronic obstructive pulmonary disease patients in India. Niger Med J. 2013;54(5):295-301.

32. Vazquez E, Mar Gomez Punter R, Giron Moreno R, Sanchez S, Lopez Riolobos C, Ancochea Bermudez J. Biochemical markers of bone turnover in chronic obstructive pulmonary disease (COPD) [abstract] Chest. 2014;145(Suppl 3):abstract 389A.

33. Romme EA, Smeenk FW, Rutten EP, Wouters EF. Osteoporosis in chronic obstructive pulmonary disease. Expert Rev Respir Med. 2013;7(4):397-410.

34. Negi H, Sarkar M, Raval AD, Pandey K, Das P. Health-related quality of life in patients with chronic obstructive pulmonary disease in North India. J Postgrad Med. 2014;60(1):7-11.

35. Miravitlles M, Cantoni J, Naberan K. Factors associated with a low level of physical activity in patients with chronic obstructive pulmonary disease. Lung. 2014;192(2):259-265.

36. Barriga S, Rodrigues F, Barbara C. Factors that influence physical activity in the daily life of male patients with chronic obstructive pulmonary disease. Rev Port Pneumol. 2014;20(3):131-137.

37. Tselebis A, Kosmas E, Bratis D, et al. Contribution of psychological factors in dropping out from chronic obstructive pulmonary disease rehabilitation programs. Biomed Res Int. 2014;2014:401326.

38. Miyazaki M, Nakamura H, Chubachi S, et al. Analysis of comorbid factors that increase the COPD assessment test scores. Respir Res. 2014;15:13.

39. Wisniewski D, Porzezinska M, Gruchała-Niedoszytko M, Niedoszytko M, Słominski JM, Jassem E. Factors influencing adherence to treatment in COPD patients and its relationship with disease exacerbations. Pneumonol Alergol Pol. 2014;82(2):96-104.

40. Chrystyn H, Small M, Milligan G, Higgins V, Gil EG, Estruch J. Impact of patients' satisfaction with their inhalers on treatment compliance and health status in COPD. Respir Med. 2014;108(2):358-365.

41. Bryant L, Bang C, Chew C, Baik SH, Wiseman D. Adequacy of inhaler technique used by people with asthma or chronic obstructive pulmonary disease. J Prim Health Care. 2013;5(3):191-198.

42. Coxson HO, Leipsic J, Parraga G, Sin DD. Using pulmonary imaging to move chronic obstructive pulmonary disease beyond $\mathrm{FEV}_{1}$. Am J Respir Crit Care Med. Epub May 29, 2014.

43. Mohamed Hoesein FA, Schmidt M, Mets OM, et al. Discriminating dominant computed tomography phenotypes in smokers without or with mild COPD. Respir Med. 2014;108(1):136-143.

44. de-Torres JP, Casanova C, Marin JM, et al. Exploring the impact of screening with low-dose $\mathrm{CT}$ on lung cancer mortality in mild to moderate COPD patients: a pilot study. Respir Med. 2013;107(5):702-707. 
Video abstract

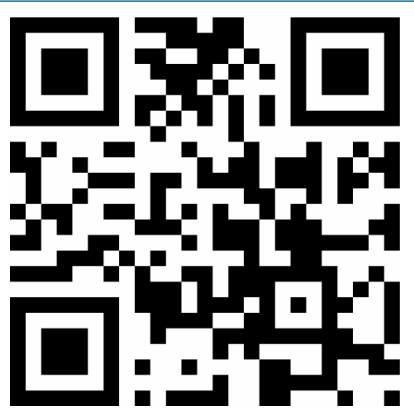

Point your SmartPhone at the code above. If you have a

QR code reader the video abstract will appear. Or use: http://dvpr.es/ItgUpXO

\section{Publish your work in this journal}

The International Journal of COPD is an international, peer-reviewed journal of therapeutics and pharmacology focusing on concise rapid reporting of clinical studies and reviews in COPD. Special focus is given to the pathophysiological processes underlying the disease, intervention programs, patient focused education, and self manage- ment protocols. This journal is indexed on PubMed Central, MedLine and CAS. The manuscript management system is completely online and includes a very quick and fair peer-review system, which is all easy to use. Visit http://www.dovepress.com/testimonials.php to read real quotes from published authors. 